SIMPÓSIO DOS

PROFISSIONAIS DA

UNICAMP

\section{ACESSO À INFORMAÇÃO E A TRANSPARÊNCIA PÚBLICA: VISIBILIDADE DAS INFORMAÇÕES DO SBU POR MEIO DO RELATÓRIO GERENCIAL \\ ESTATÍSTICO DO SISTEMA DE BIBLIOTECAS DA UNICAMP}

MARIANA PEDROSO TEIXEIRA, KEITE APARECIDA DUARTE, LUDGERO SCOCIA JUNIOR, GILMAR VICENTE, DANIELA FEIJÓ SIMÕES, VALÉRIA DOS SANTOS GOUVEIA MARTINS, OSCAR ELIEL

BIBCE - BIBLIOTECA CENTRAL;BCOM - BIBLIOTECA COMUNITARIA;TIS - SUPORTE;

Introdução:

O presente trabalho tem como objetivo apresentar a segunda versão do Relatório Gerencial Estatístico do Sistema de Bibliotecas da UNICAMP (SBU). As novas tecnologias da informação e comunicação mudaram a forma como as informações passaram a ser geradas, armazenadas e disseminadas. Essas mudanças oferecem maior dinamismo e autonomia aos seus usuários. Para se adequar a essas mudanças, o SBU implantou, em 2012, o Relatório Gerencial Estatístico. Esse sistema disponibiliza, em um único local, indicadores consolidados sobre Acervo, Infraestrutura e Serviços oferecidos pelo SBU. Após a implantação mudanças pontuais foram realizadas, mas tornou-se necessária a projeção de novas planilhas para divulgação de novos serviços e atendimento às diretrizes da Lei de Acesso à Informação (LAI).

\title{
Metodologia:
}

Foram realizados encontros com as áreas vinculadas à coordenadoria do SBU para mapear novos serviços; análise dos portais web das bibliotecas e identificação dos dados necessários para alimentação do Portal de Transparência da UNICAMP. A linguagem de programação utilizada é PHP 7.x, banco de dados MariaDB Server 5.5.60, em servidor Linux Centos 7, Apache 2.4.6. Para a exibição de gráficos optou-se pelo software ElasticSearch 7.2 e Kibana 7.2.

\section{Resultados:}

A nova versão do Relatório permite a visualização de dados estatísticos por meio de planilhas em Excel e gráficos. $O$ acesso para preenchimento do sistema ocorre via Web por meio de usuário e senha. Atualmente são três níveis de acesso: Desenvolvimento, Administração e Bibliotecas do Sistema. A consulta pública dos dados consolidados pode ser feita via Portal Web do SBU. As novas planilhas implementadas são: Ação cultural; Manutenção e Conservação Predial; Serviços do Laboratório de Acessibilidades; Projetos; Serviços de Referência (Apoio ao Pesquisador e Docente, Artigos com custos subsidiários, Assistência ao usuário, Capacitação de Usuários, Ficha catalográfica); Serviços de Manutenção e Desenvolvimento de sistemas; Aquisições, Atas de Registro de Preço, Contratos e Convênios; Execução Orçamentária e Financeira; Acervo (Aquisições e recursos financeiros, Análises Bibliométricas, Uso de Fontes eletrônicas); Alimentação e Acesso ao Repositório Institucional e Repositório Acessível da UNICAMP e Portal de Periódicos Eletrônicos Científicos.

\section{Considerações finais:}

A nova versão do Relatório permitirá ao SBU disponibilizar informações atualizadas e de maneira confiável para apoiar as atividades de planejamento, gestão e tomadas de decisão. Em atendimento à LAI, Lei nำ12.527/11, assegurará o direito de informações públicas e aberta a todos nas planilhas sobre aquisições, atas de registro de preço, contratos e convênios e execução orçamentária e financeira.

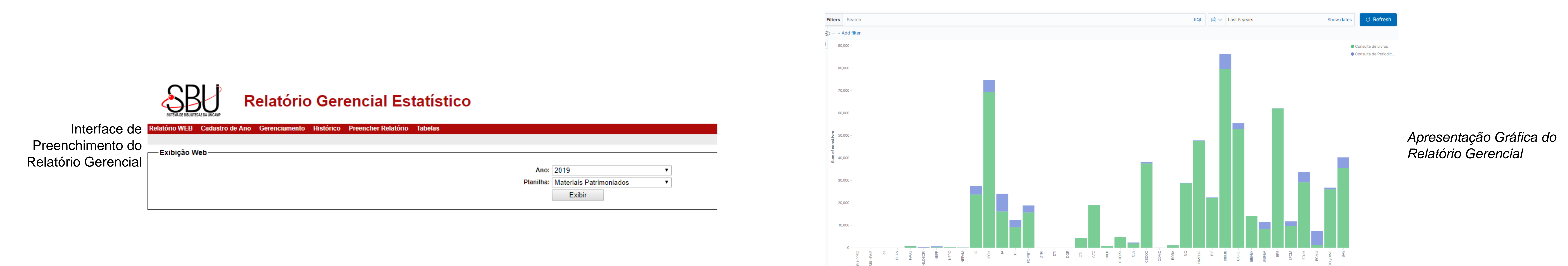

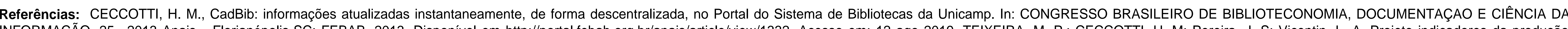

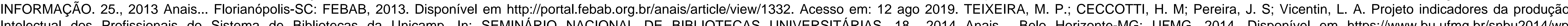
content/uploads/trabalhos/583-2362.pdf. Acesso em: 12 ago 2019.

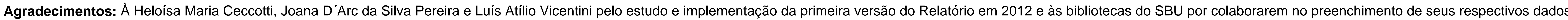

